from three shark species into a model of terrestrial animal movement, Yannis Papastamatiou at the University of Florida in Gainesville and his colleagues found that tiger sharks (Galeocerdo cuvier) made 'directed walks' at scales of 6-8 kilometres, and thresher sharks (Alopias vulpinus) did so at scales of 400-1,900 metres. Both species have large home ranges.

In contrast, reef sharks (Carcharhinus melanopterus) have small home ranges and they showed random, unoriented movement at the scales examined.

The findings could help to predict how sharks will disperse in the face of future challenges such as overfishing and climate change, the authors say.

J. Anim. Ecol. doi: 10.1111/

j.1365-2656.2011.

01815.x (2011)

\section{MATERIALS \\ Solar cells take a stretch}

Electronics made of organic materials such as plastic are appealing because of their flexibility and their ability to be used in biological systems, textiles and moving machine parts. Zhenan Bao and her colleagues at Stanford University in California have made the first intrinsically stretchable organic solar cells.

They created the devices by depositing organic films used in previous organic photovoltaics on a prestretched rubber base that they then allowed to compress. This introduced buckling waves in the films that made them stretchable.

The team found that the resulting solar cells remained completely functional when stretched lengthwise by up to $27 \%$. Surprisingly, the cells' performance did not depend on the amount by which they were stretched.

\section{A changing eye on the world}

The eyes of most animal groups use one of two types of light-sensing cell — rhabdomeric or ciliary photoreceptors. Scientists had thought that ciliary photoreceptors, which include the rods and cones of the human retina, were unique to the eyes of chordates animals with a backbone precursor. In non-chordates, this cell type had only ever been found in the brain or other body structures.

Now, Yale Passamaneck at the University of Hawaii at Manoa and his colleagues have found evidence of ciliary cells in the eyes of larvae of Terebratalia transversa, a member of an ancient group of non-chordates, by showing expression of a key ciliary gene for a light-sensitive protein in the eyes. The discovery could mean that the use of these cells to sense directional light evolved more than once.

EvoDevo doi:10.1186/20419139-2-6 (2011)

\section{MICROBIOLOGY \\ Tagging the TB bacterium}

The fight against tuberculosis lacks an important weapon: a sensitive and specific diagnostic probe for the causal bacterium, Mycobacterium tuberculosis.

Clifton Barry at the National Institutes of Health in Bethesda, Maryland, Benjamin Davis at the University of Oxford, UK, and their co-workers have got around the problem by exploiting an enzymatic reaction that adds the sugar trehalose to the bacterium's surface lipids.

They synthesized a library of small molecules similar to trehalose and tested their ability to act as substrates in this reaction. One of these molecules, FITC-trehalose, which is fluorescent, was incorporated

COMMUNITY CHOICE

\title{
CANCER
}

\section{Stressing out cancer cells}

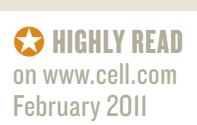

A chemical screen has yielded three compounds that kill cells with abnormal numbers of chromosomes - a common feature of cancer cells.

Angelika Amon and her colleagues at the Massachusetts Institute of Technology in Cambridge looked for compounds that block proliferation of mouse cells with extra chromosomes, but that do not affect normal cells.

They found three such compounds, all of which also triggered programmed cell death in the abnormal cells. Two of the chemicals, called AICAR and 17-AAG, also inhibited the growth of human cancer cells with abnormal chromosomes. AICAR stimulates the protein $\mathrm{p} 53$, which regulates cell death, and may also exacerbate the stress that these cells experience as a result of the production of excess protein from their extra chromosomes. Cell 144, 499-512 (2011)

into the cell envelope and 'lit up' bacteria grown in its presence. FITC-trehalose also labelled M. tuberculosis living inside macrophages, a type of immune-system cell it frequently infects. The authors say that this technique could be used to follow how the bacterium infects macrophages.

Nature Chem. Biol. doi:10.1038/ nchembio.539 (2011)

\section{ARCHAEOLOGY \\ Stone Age home by the sea}

Some early Americans preferred to stay close to the sea, judging by discoveries on the Channel Islands off the coast of southern California. These ancient hunting grounds have yielded small stone tools as well as abundant remains of fish, seabirds and shellfish.

Jon Erlandson at the University of Oregon in Eugene and his team dated three sites to between about 12,000 and 11,000 years ago. They found bones from geese, cormorants, albatross, fish and marine mammals, along with the shells of mussels, crabs and abalone.

The hunters must have

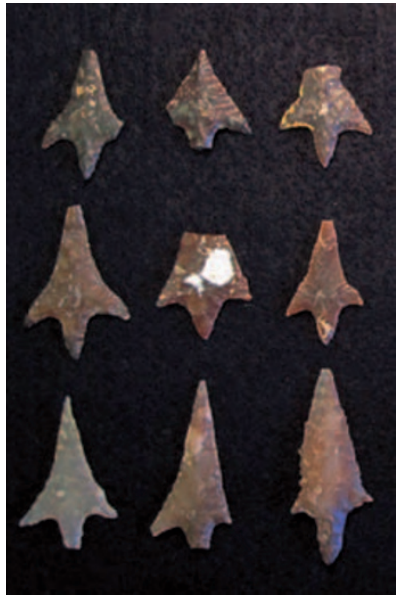

reached the islands by boat, but neither their boats nor human burials have been found.

However, their projectile points (pictured) look different from the stone tools made by inland peoples from the Clovis culture, and so are unlikely to have derived from that source. The Channel Island sites support the idea that humans settled the Americas while skirting the Pacific coast. Science 331, 1181-1184 (2011) For a longer story on this research, see go.nature.com/cczpua

\section{$\rightarrow$ NATURE.COM}

For the latest research published by Naturevisit:

www.nature.com/latestresearch 